\title{
BMJ open Self-diagnosis of influenza during a pandemic: a cross-sectional survey
}

\author{
Annemarie Jutel, ${ }^{1}$ Michael G Baker, ${ }^{2}$ James Stanley, ${ }^{2}$ Q Sue Huang, ${ }^{3}$ \\ Don Bandaranayake ${ }^{4}$
}

To cite: Jutel A, Baker MG, Stanley J, et al.

Self-diagnosis of influenza during a pandemic:

a cross-sectional survey. BMJ Open 2011;1:e000234. doi:10.1136/bmjopen-2011000234

- Prepublication history for this paper is available online. To view these files please visit the journal online (http:// bmjopen.bmj.com).

Received 28 June 2011 Accepted 20 July 2011

This final article is available for use under the terms of the Creative Commons Attribution Non-Commercial 2.0 Licence; see http://bmjopen.bmj.com

${ }^{1}$ Graduate School of Nursing, Midwifery and Health, Victoria University of Wellington, Wellington, New Zealand

${ }^{2}$ Department of Public Health, University of Otago, Wellington, New Zealand ${ }^{3}$ Department of Public Health, University of Otago, Wellington, New Zealand ${ }^{4}$ WHO National Influenza Centre, Institute of Environmental Science and Research, Upper Hutt, New Zealand

Correspondence to Dr Annemarie Jutel; annemarie.jutel@vuw.ac.nz

\section{ABSTRACT}

Background: Self-diagnosis of influenza is an important component of pandemic control and management as it may support self-management practices and reduce visits to healthcare facilities, thus helping contain viral spread. However, little is known about the accuracy of self-diagnosis of influenza, particularly during pandemics.

Methods: We used cross-sectional survey data to correlate self-diagnosis of influenza with serological evidence of 2009 pandemic influenza $A(H 1 N 1)$ infection (haemagglutination inhibition titres of $\geq 1: 40$ ) and to determine what symptoms were more likely to be present in accurate self-diagnosis. The sera and risk factor data were collected for the national $A(H 1 N 1)$ seroprevalence survey from November 2009 to March 2010, 3 months after the first pandemic wave in New Zealand (NZ).

Results: The samples consisted of 318 children, 413 adults and 423 healthcare workers. The likelihood of being seropositive was no different in those who believed they had influenza from those who believed they did not have influenza in all groups. Among adults, 23.3\% (95\% $\mathrm{Cl} 11.9 \%$ to $34.7 \%$ ) of those who reported having had influenza were seropositive for H1N1, but among those reporting no influenza, $21.3 \%$ (95\% Cl $13 \%$ to $29.7 \%$ ) were also seropositive. Those meeting NZ surveillance or Ministry of Health influenza case definitions were more likely to believe they had the flu (surveillance data adult sample OR 27.1, 95\% Cl 13.6 to 53.6), but these symptom profiles were not associated with a higher likelihood of H1N1 seropositivity (surveillance data adult sample OR $0.93,95 \% \mathrm{Cl} 0.5$ to 1.7 ).

Conclusions: Self-diagnosis does not accurately predict influenza seropositivity. The symptoms promoted by many public health campaigns are linked with self-diagnosis of influenza but not with seropositivity. These findings raise challenges for public health initiatives that depend on accurate selfdiagnosis by members of the public and appropriate self-management action.

\section{BACKGROUND}

Self-diagnosis is an important component of pandemic control and management. The use of self-diagnosis in an influenza pandemic can prevent some exposures by reducing outpatient visits to primary care clinics. ${ }^{1}$ During the 2009 pandemic, following

\section{ARTICLE SUMMARY}

\section{Article focus}

- To determine whether lay people can accurately recognise influenza infection.

\section{Key messages}

- Individuals meeting influenza case definitions were more likely to believe they had influenza.

- Self-diagnosis, whether by a lay person or a healthcare worker, did not accurately predict influenza seropositivity.

\section{Strengths and limitations of this study}

- This is the first published study of the effectiveness of self-diagnosis of influenza compared with laboratory evidence of infection in a broad population-based sample during a pandemic.

- Some of the participants who believed they had the flu may have had a seasonal influenza or other respiratory pathogens (although H1N1 was the dominant influenza strain).

- This survey was based on symptom recall rather than symptom reports, which may reflect the participants' enduring perceptions of influenza, likely to guide their behaviour in future influenza epidemics.

Centers for Disease Control recommendations, patient teaching brochures advised patients to stay at home and avoid contact with other people if they had influenza like illness (ILI), seeking medical assistance only in case of complications or risk factors. While the accuracy of self-diagnosis has been studied for a range of common diseases (eg, uncomplicated urinary tract infections, ${ }^{2}{ }_{3}$ vaginal yeast infections ${ }^{4}$ and malaria ${ }^{5}{ }^{6}$ ), it has not been established for influenza.

Although self-diagnosis of influenza is clearly desirable for the purposes of infection containment, it also presents challenges for patients and doctors alike. As the social science literature clearly articulates, diagnosis is central to the practice of medicine and to defining the roles of, and boundaries between, the patient and the professional; however, self-diagnosis blurs these distinctions. $^{7-10}$ 
The diagnosis of influenza by a lay person may be independent of medical contact, using resources such as family, friends or other non-medical sources of information, for example on-line or internet resources (independent self-diagnosis). It may also be supported by a health professional via a helpline without the lay person being seen for a clinical diagnosis (assisted self-diagnosis).

The purpose of this study was to determine whether lay people's assessment of influenza status is confirmed by serological testing, and whether the presence of particular symptoms assists individuals in the correct identification of influenza. It also aimed to measure the accuracy of self-diagnosis by healthcare workers (HCW). Establishing the current reliability of self-diagnosis will either provide assurances about, or identify shortcomings in, public health strategies to contain the spread of influenza.

\section{METHODS}

Population sample

This study was conducted as part of the national Environmental Science and Research (ESR) seroprevalance study in early $2010 .{ }^{11}$ This study used a purposive, multistage random cross-sectional survey of 1147 subjects from selected primary care patient registers from 14 general practitioner (GP) practices. The practices were selected purposively on the basis of observed high, medium and low incidence during the pandemic and on ethnic distribution. Each practice was stratified by age and by ethnic group. Within each stratum, simple random sampling was undertaken, with oversampling in strata for Māori and Pacific respondents to improve the precision of estimates for these groups. A second sample consisted of 540 HCW (369 HCW located in Auckland and Middlemore Hospitals, and 171 from the 14 GP practices in the community study). The HCW sample included medical, nursing and other staff. A simple random sampling procedure was performed to select participants for this sample. ${ }^{11}$ Sera and risk factor data were collected from November 2009 to March 2010, 3 months after the first pandemic wave in New Zealand $(\mathrm{NZ}) .{ }^{12}$ Ethics approval (MEC/09/09/106) was obtained from the Multiregional Ethics Committee of the NZ Ministry of Health. Written informed consent was obtained from all participants. ${ }^{11}$

We excluded participants born before 1957 because of the higher level of pre-pandemic seropositivity in this group. ${ }^{11}$ We treated those under age 18 as a separate group because their questionnaires were usually completed by parents (self-diagnosis by proxy) and their health-related behaviours were likely influenced or, for the very young, entirely managed by their parents.

We also considered HCW separately from lay participants; however, as the sampling methods for this group were different from the main community sample (the geographical area was more restricted in the HCW sample), comparisons between this group and the adult community sample should be made with caution.

\section{Laboratory testing}

Blood samples were obtained by phlebotomists in the GP clinics, and serological testing was carried out at the National Influenza Centre at ESR using a haemagglutination inhibition assay in line with the standard protocol provided by the WHO Collaborating Centre in Melbourne. Haemagglutination inhibition titres of $\geq 40$ against H1N1 were considered seroprotective as well as seropositive. Laboratory testing methods are fully described elsewhere. ${ }^{11}$

\section{Questionnaire}

A questionnaire was administered by nurses from 14 participating GP clinics at the time of the blood sample collection in order to record information about respondent demographics, whether respondents believed they had contracted influenza in 2009 and their symptoms. Questions were both multiple-choice and open-ended.

Respondents were asked 'Did you have the flu or influenza over this last winter (June to August)?', with options being 'yes', 'possibly', 'no' and 'don't know'. Those who believed they had had influenza were asked how they knew, choosing either:

1. I could tell on my own or with the help of my family and friends

2. I called the nurse or HealthLine and they helped me to decide, or

3. I saw my doctor or other health professional who told me I did.

Self-diagnosis was defined as including both independent and assisted forms (ie, choosing 1 or 2 above) for those who responded 'yes' to the question about having had influenza.

Two additional case definitions of influenza were used based on reported symptoms: ILI defined by the NZ sentinel surveillance definition ${ }^{13}$ of two or more symptoms from fever, muscle ache and headache (reports of chills are included in this definition, but this information was not collected in this study) and also by the NZ Ministry of Health ${ }^{14}$ as fever, plus cough or sore throat (reports of chills or sweating are included in this definition, but this information was not collected in the study).

Demographic information included age, gender, selfidentified ethnicity and socioeconomic deprivation (using NZDep, a well-validated measure of small-area socioeconomic deprivation based on census-derived characteristics such as income, education and household crowding, and assigned according to domicile $\operatorname{address}^{15}$ ). Ethnicity classification used the NZ 2006 Census questions, and prioritised ethnicity coding according to Ministry of Health ethnicity data protocols. ${ }^{16}$ Participants could choose up to nine different symptoms (fever or high temperature; cough; sore 
throat; runny nose; red, watery or sore eye(s); headache; muscle aches and pains; weakness, tiredness or fatigue; an upset stomach, diarrhoea or vomiting, to describe any illness they had during the period under study as well as the open-ended 'something else (describe)'.

\section{Analysis}

All statistical analyses were performed using SAS V.9.2. Survey analysis techniques were used to take into account differential sampling probabilities by age and ethnicity; sample weights were calculated by ESR as the inverse probability of selection of an individual within each GP practice.

Proportions (and 95\% CI) were calculated using the Surveyfreq procedure, taking into account clustering by GP practice and sample weight (as described above) for the adult/child community samples. $\chi^{2}$ Comparisons for the complex survey data (seroprevalence community survey) were adjusted using the Rao-Scott correction ${ }^{17}$ to allow for the impact of the complex survey structure and to test whether seropositivity rates were different between the three self-reported influenza status groups, and also to test whether seropositivity status differed according to the decision making process by which a respondent had decided that he or she (or their child) had influenza. As the HCW dataset did not derive from a complex sampling method, Pearson's $\chi^{2}$ tests were used for the equivalent hypothesis tests for that group.

Sensitivity and specificity (along with positive predictive value (PPV) and negative predictive value (NPV)) were calculated for seropositive status as the 'gold standard' measure of disease status, and three definitions of influenza 'screening' tests: self-report, Ministry of Health case definition, and NZ sentinel surveillance case definition. Self-reported influenza status was reclassified as a binary variable by combining 'definite' and 'possibly' groups into a 'positive self-report' group for the purposes of this analysis. We opted for this reconfiguration because we felt it was the most policy-relevant categorisation and would potentially translate into useful health advice (either of these groups was likely to implement influenza-related management strategies). All of these calculations and CIs were performed using the Proc Surveyfreq command.

Logistic regression methods (Proc Surveylogistic) were used to investigate the relationships between case definition status (separate models for the different definitions) and (1) self-reported influenza status or (2) seropositive test results.

\section{RESULTS}

\section{Characteristics of the sample}

For the community branch of the study, a minimum sample size of 1500 subjects was required at a design prevalence of $20 \%$ and a confidence level of $95 \%$ to maintain a $\pm 10 \%$ margin error of estimate. A total of 1147 subjects participated fully in the study (nine did not return the questionnaire and were thus excluded from the analysis). This gave a target rate of $76 \%$. For the HCW branch of the study, the minimum sample size was calculated using the same criteria as for the community study. The number of subjects (171 primary HCW and 369 secondary HCW) exceeded the minimum requirement. Of the 1687 subjects with completed questionnaires and serological results across the community and HCW studies, after excluding those respondents born before 1957, 413 responses (unweighted frequency) were considered for the analyses of adult responses. In addition, 318 responses concerning children were considered and $423 \mathrm{HCW}$ responses. This gave a final sample size of 1154 people across the three groups.

The baseline demographic characteristics of the study populations are shown in table 1 . These are unweighted frequencies and percentages; all subsequent analyses take the sampling structure into account. ${ }^{11}$ The sample was not adequately powered to demonstrate ethnic differences in the findings reported below.

\section{Accuracy of self-report of influenza}

Seropositivity status was compared across the three selfreported influenza status groups (yes, no or possibly had the flu in 2009). Respondents who answered 'don't know' to this question $(\mathrm{n}=16,21$ and 22 for adult, child and HCW samples, respectively) were excluded from this analysis. As shown in table 2, the likelihood of being seropositive was not significantly different between the three self-reported influenza status groups in any of the three sample groups. For adults in the community sample, point estimates of seropositive status ranged from $21.3 \%$ to $25.1 \%$ across the three self-report groups; for under $18 \mathrm{~s}$ in the same sample, seropositive rates were between $40.1 \%$ and $45.9 \%$, which was the highest among all three sample groups; and for HCW, the range was between $25.7 \%$ and $33.0 \%$ seropositive.

Table 3 shows that among those study subjects who reported having had influenza, the proportion of people who were seropositive was higher among those who reached a decision in conjunction with a health professional than among those who reported reaching a diagnosis on their own (including using a telephone helpline). While this pattern was consistent across all three sample sources, none of these differences were statistically significant (all $\mathrm{p}>0.3$ ), which possibly reflects the smaller sample sizes for this analysis.

As shown in table 4, self-reported flu status performed poorly as a screening tool for H1N1 infection, failing to detect the majority of those who were seropositive (adult sensitivity $45.7 \%$ ). Only about a quarter of those who considered themselves to have had influenza during the preceding winter showed serological evidence of infection (adult PPV 24.1\%). Self-reported flu status had higher sensitivity and lower specificity than the Ministry of Health and NZ sentinel surveillance case definitions. Screening performance (sensitivity, specificity, PPV and NPV) was otherwise broadly similar across the three sets of 'screening' criteria used. PPV and NPV values across 
Table 1 Demographic characteristics of participants (unweighted frequencies and percentages)

\begin{tabular}{|c|c|c|c|c|c|c|}
\hline \multirow[b]{2}{*}{ Factor } & \multicolumn{2}{|c|}{ Adults $(18+$ years) $(n=413)$} & \multicolumn{2}{|c|}{ Children $(<18$ years) $(n=318)$} & \multicolumn{2}{|c|}{ Healthcare workers $(n=423)$} \\
\hline & Frequency & Percentage $^{\star}$ & Frequency & Percentage* & Frequency & Percentage* \\
\hline \multicolumn{7}{|l|}{ Sex } \\
\hline Female & 262 & 63.44 & 150 & 47.62 & 348 & 82.27 \\
\hline Male & 151 & 36.56 & 165 & 52.38 & 75 & 17.73 \\
\hline Unknown & 0 & & 3 & & 0 & \\
\hline \multicolumn{7}{|l|}{ Ethnicity } \\
\hline NZE† & 160 & 47.76 & 95 & 42.22 & 289 & 68.97 \\
\hline Māori & 82 & 24.48 & 53 & 23.56 & 20 & 4.77 \\
\hline Pacific & 65 & 19.40 & 54 & 24.00 & 14 & 3.34 \\
\hline Asian & 22 & 6.57 & 17 & 7.56 & 92 & 21.96 \\
\hline Other & 6 & 1.79 & 6 & 2.67 & 4 & 0.95 \\
\hline Unknown & 78 & & 93 & & 4 & \\
\hline \multicolumn{7}{|c|}{ Age group, years } \\
\hline $1-4$ & & & 150 & 47.17 & & \\
\hline $5-9$ & & & 68 & 21.38 & & \\
\hline $10-14$ & & & 68 & 21.38 & & \\
\hline $15-17$ & & & 32 & 10.06 & & \\
\hline $18-24$ & 80 & 19.37 & & & 26 & 6.15 \\
\hline $25-34$ & 101 & 24.46 & & & 137 & 32.39 \\
\hline $35-44$ & 132 & 31.96 & & & 152 & 36.17 \\
\hline $45-52^{*}$ & 100 & 24.21 & & & 107 & 25.30 \\
\hline
\end{tabular}

all definitions followed the pattern seen for seropositive prevalence (eg, children had the highest PPV, reflecting a higher proportion of seropositive tests).

Seropositive status, symptom profiles and case definitions of influenza

Using Ministry of Health and the NZ sentinel surveillance ILI case definitions, we sought to confirm whether there was an increased likelihood of seropositivity for those who met these case definitions, based on selfreport of symptoms. The likelihood of being seropositive was not significantly different between these symptom profile groups for any sample group (see table 5; 95\% CIs for all ORs included 1). People who met a case definition had a much greater likelihood of selfreporting having had influenza (table 5, for both definitions).

\section{DISCUSSION}

Key findings

To our knowledge, this is the first published study of the effectiveness of self-diagnosis of influenza compared with laboratory evidence of infection in a broad

Table 2 Serological status according to self-reported flu status (proportions and $95 \% \mathrm{Cl}$ )

\begin{tabular}{|c|c|c|c|c|}
\hline Self-reported flu status & $\mathbf{n}$ & $\%$ Seropositive* & $95 \% \mathrm{Cl}$ & p Value $†$ \\
\hline \multicolumn{5}{|l|}{ Adults $(18+$ years $) \neq(n=413)$} \\
\hline No & 221 & 21.3 & 13.0 to 29.7 & \multirow[t]{3}{*}{0.802} \\
\hline Possibly & 68 & 25.1 & 14.2 to 36 & \\
\hline Yes & 108 & 23.3 & 11.9 to 34.7 & \\
\hline \multicolumn{5}{|c|}{ Children $(<18$ years $) \S(n=318)$} \\
\hline No & 149 & 45.9 & 34.4 to 57.4 & \multirow[t]{3}{*}{0.723} \\
\hline Possibly & 55 & 42.2 & 28.6 to 55.9 & \\
\hline Yes & 86 & 40.1 & 24.7 to 55.6 & \\
\hline \multicolumn{5}{|c|}{ Healthcare workers $₫(n=423)$} \\
\hline No & 222 & 25.7 & 20.1 to 31.9 & \multirow[t]{3}{*}{0.415} \\
\hline Possibly & 80 & 27.5 & 18.1 to 38.6 & \\
\hline Yes & 94 & 33.0 & 23.6 to 43.4 & \\
\hline
\end{tabular}


Table 3 Serological status according to diagnostic approach for people self-reporting having had influenza

\begin{tabular}{|c|c|c|c|c|}
\hline Method of diagnosis & $\mathbf{n}$ & $\%$ Seropositive* & $95 \% \mathrm{Cl}$ & p Value $\dagger$ \\
\hline \multicolumn{5}{|c|}{ Adults $(18+$ years $) \neq(n=108)$} \\
\hline Health professional & 37 & $27.1 \%$ & (7.9 to 46.3$)$ & \multirow[t]{2}{*}{0.392} \\
\hline Self-diagnosis & 61 & $17.7 \%$ & (5.3 to 30.1$)$ & \\
\hline \multicolumn{5}{|c|}{ Children $(<18$ years $) \S(n=86)$} \\
\hline Health professional & 43 & $39.7 \%$ & (18.4 to 61.1$)$ & \multirow[t]{2}{*}{0.332} \\
\hline Self-diagnosis & 34 & $25.2 \%$ & (4.5 to 45.9$)$ & \\
\hline \multicolumn{5}{|c|}{ Healthcare workers $(n=94)$} \\
\hline Health professional & 25 & $40.0 \%$ & (21.1 to 61.3 ) & \multirow[t]{2}{*}{0.356} \\
\hline Self-diagnosis & 67 & $29.9 \%$ & (19.3 to 42.3 ) & \\
\hline
\end{tabular}

population-based sample during a pandemic. The likelihood of being seropositive was no different in those who believed they had influenza from those who believed they did not have influenza. This finding applied to HCW as well as adults and children. Our study showed that self-diagnosis in a NZ population lacks sensitivity and specificity for diagnosing influenza. The poor sensitivity may lead people with influenza to believe that they are well and therefore to fail to take measures to limit their contribution to influenza spread. The lack of specificity may result in delayed medical treatment when serious treatable illness is present. ${ }^{18}$

\section{Strengths and weaknesses of the study}

Limitations of this study include the fact that some of the participants who believed they had the flu and yet were seronegative for H1N1 may have had seasonal influenza or other respiratory pathogens. However, H1N1 was the dominant influenza strain in 2009, accounting for $77.6 \%$ of influenza viruses that were sub-typed during the year. $^{19}$ Further, the fact that seasonal influenza was replaced very quickly by pandemic $\mathrm{H} 1 \mathrm{~N} 1$ reduces this limitation to some extent. A small proportion of those who were seropositive will have baseline immunity to H1N1 acquired prior to 2009, although testing of stored

Table 4 Screening performance of influenza definitions for detecting seropositive status (sensitivity, specificity, PPV and NPV)

\begin{tabular}{|c|c|c|c|}
\hline Measure & $\begin{array}{l}\text { NZ sentinel surveillance ILI } \\
\text { definition* } \\
\text { Point estimate }(95 \% \mathrm{Cl})\end{array}$ & $\begin{array}{l}\text { NZ Ministry of Health ILI } \\
\text { definition } \dagger \\
\text { Point estimate }(95 \% \mathrm{CI})\end{array}$ & $\begin{array}{l}\text { Self-reported flu status } \neq \\
\text { Point estimate }(95 \% \mathrm{Cl})\end{array}$ \\
\hline \multicolumn{4}{|c|}{ Adults $(18+$ years $) \S(n=413)$} \\
\hline Sensitivity & $37.7(25.5$ to 50.0$)$ & $38.0(25.6$ to 50.4$)$ & 45.7 (33.0 to 58.3$)$ \\
\hline Specificity & 60.5 (53.6 to 67.4$)$ & $67.2(60.6$ to 73.8$)$ & 58.1 (51.0 to 65.3$)$ \\
\hline PPV & 21.6 (13.6 to 29.6$)$ & 25.1 (15.8 to 34.4$)$ & 24.1 (16.2 to 31.9$)$ \\
\hline NPV & 77.1 (70.6 to 83.5$)$ & 79.0 (73.1 to 84.8$)$ & 78.7 (72.0 to 85.3$)$ \\
\hline \multicolumn{4}{|c|}{ Children $(<18$ years $) \uparrow(n=318)$} \\
\hline Sensitivity & $32.5(21.0$ to 44.0$)$ & $36.0(24.5$ to 47.6$)$ & $42.4(30.0$ to 54.9$)$ \\
\hline Specificity & 68.4 (58.4 to 78.4$)$ & 57.2 (47.3 to 67.1$)$ & 52.6 (42.1 to 63.0$)$ \\
\hline PPV & $43.4(29.1$ to 57.7$)$ & $38.6(27.0$ to 50.1$)$ & 40.9 (29.3 to 52.6$)$ \\
\hline NPV & $57.6(48.2$ to 67.0$)$ & 54.5 (44.0 to 65.0$)$ & 54.1 (43.0 to 65.3$)$ \\
\hline \multicolumn{4}{|c|}{ Healthcare workers ${ }^{\star \star}(n=423)$} \\
\hline Sensitivity & $32.5(23.8$ to 41.1$)$ & 30.7 (22.2 to 39.2$)$ & 48.2 (38.8 to 57.6$)$ \\
\hline Specificity & 70.8 (65.7 to 75.9$)$ & 76.4 (71.6 to 81.2$)$ & 57.7 (51.9 to 63.4$)$ \\
\hline PPV & 29.9 (21.9 to 37.9$)$ & 32.7 (23.8 to 41.6$)$ & 30.5 (23.6 to 37.3$)$ \\
\hline NPV & 73.5 (68.5 to 78.6$)$ & 74.7 (69.8 to 79.5$)$ & 74.3 (68.6 to 80.1$)$ \\
\hline \multicolumn{4}{|c|}{$\begin{array}{l}\text { *Two or more symptoms from: fever, muscle ache and headache. } \\
\text { †Fever, plus cough and/or sore throat. } \\
\text { †Self-diagnosis, assisted-self-diagnosis or self-diagnosis by proxy. } \\
\text { SAdults: } 16 \text { 'don't know' respondents on self-reported influenza status were excluded from analysis. } \\
\text { †Children: } 21 \text { 'don't know' respondents on self-reported influenza status were excluded from analysis. } \\
\text { **Healthcare workers: } 22 \text { 'don't know' respondents on self-reported influenza status and five respondents missing immunological status were } \\
\text { excluded from analysis. } \\
\text { ILI, influenza like illness; NPV, negative predictive value; NZ, New Zealand; PPV, positive predictive value. }\end{array}$} \\
\hline
\end{tabular}


Table 5 Association between symptom profiles and self-reported flu status and seropositive status

Self-report status

OR $(95 \% \mathrm{Cl})$

Seropositive status OR $(95 \% \mathrm{Cl})$

\begin{tabular}{|c|c|c|}
\hline \multicolumn{3}{|c|}{ NZ sentinel surveillance definitions* } \\
\hline No or 1 symptom & Reference group & Reference group \\
\hline 2 or 3 symptoms & 27.1 (13.6 to 53.6$)$ & $0.93(0.5$ to 1.7$)$ \\
\hline \multicolumn{3}{|l|}{ Children $(<18$ years $) \uparrow$} \\
\hline No or 1 symptom & Reference group & Reference group \\
\hline 2 or 3 symptoms & 21.5 (8.98 to 51.6$)$ & $1.04(0.52$ to 1.09$)$ \\
\hline \multicolumn{3}{|l|}{ Healthcare workers ${ }^{\star \star}$} \\
\hline No or 1 symptom & Reference group & Reference group \\
\hline 2 or 3 symptoms & $18.2(10.3$ to 32.1$)$ & $1.19(0.75$ to 1.9$)$ \\
\hline \multicolumn{3}{|c|}{ Ministry of Health $(\mathrm{MoH})$ definition $†$} \\
\hline \multicolumn{3}{|c|}{ Adults $(18+$ years $) \S$} \\
\hline Met $\mathrm{MoH}$ definition & 11.5 (6.1 to 21.8$)$ & 1.3 (0.7 to 2.3$)$ \\
\hline Did not meet definition & Reference group & Reference group \\
\hline \multicolumn{3}{|l|}{ Children $(<18$ years $) \Phi$} \\
\hline Met $\mathrm{MoH}$ definition & 9.5 (4.5 to 20$)$ & $0.8(0.4$ to 1.4$)$ \\
\hline Did not meet definition & Reference group & Reference group \\
\hline \multicolumn{3}{|l|}{ Healthcare workers ${ }^{\star \star}$} \\
\hline Met $\mathrm{MoH}$ definition & 13.3 (7.4 to 23.9$)$ & $1.46(0.9$ to 2.4$)$ \\
\hline Did not meet definition & Reference group & Reference group \\
\hline $\begin{array}{l}\text { is and } 95 \% \mathrm{Cl} \text { derived from } \\
\text { vo or more symptoms from: } \\
\text { ever, plus cough and/or sore } \\
\text { elf-diagnosis, assisted-self-di } \\
\text { dults: } 16 \text { 'don't know' respon } \\
\text { hildren: } 21 \text { 'don't know' respc } \\
\text { ealthcare workers: } 22 \text { 'don't } \\
\text { luded from analysis. }\end{array}$ & $\begin{array}{l}\text { nodels. } \\
\text { ee. } \\
\text { xy. } \\
\text { status were exclude } \\
\text { za status were excluc } \\
\text { rted influenza status }\end{array}$ & 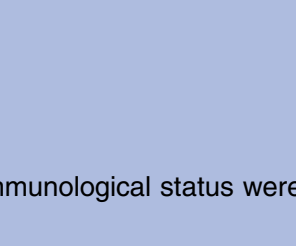 \\
\hline
\end{tabular}

sera shows that the level of such infection is low, ranging from $6.5 \%$ to $7.5 \%$ in the $20-59$-year-old population. ${ }^{11}$ Further, this survey was based on symptom recall rather than symptom reports at the time of presentation. Symptoms reported retrospectively may well not match the actual symptoms experienced during the illness. However, the pandemic was an unusual event of some concern to the individual and recall bias tends to be minimal in such situations. Furthermore, there is some validity in focusing on recalled symptoms, because these may reflect the participants' enduring perceptions of influenza, which may guide their behaviour in relation to future episodes of ILI. The higher likelihood of positive serology in those adults who consulted a health professional may be related to greater severity of their disease which this study does not capture. Also, it is likely that a higher proportion of people than usual may have consulted a healthcare provider due to the high media attention given to 'swine-flu'. The findings of this study might not be generalisable to other influenza viruses causing seasonal and pandemic disease.

\section{Strengths and weaknesses in relation to other studies}

Other studies have attempted to understand how lay people report ILI, but have not obtained medical or laboratory confirmation of the diagnosis as ours did. ${ }^{20} 21$ In excess of nine $\mathrm{H} 1 \mathrm{~N} 1$ seroprevalence studies have been carried out following the pandemic. $^{22}$ Almost all used unlinked specimens and so were not able to question participants about their symptom history. ${ }^{23-26}$ Two studies in selected military populations collected symptom data. One prospective study of Singaporean military personnel tracked symptomatic illness during the pandemic and found that less than a third of those who were seropositive reported symptoms. ${ }^{27} \mathrm{~A}$ small cross-sectional study reported seroconversion following an H1N1 outbreak in a Finnish military garrison, and found that sensitivity for seropositivity was $50 \%$ on the basis of self-reported upper respiratory tract infection symptoms (ie, half of those with serological evidence of infection reported a history of upper respiratory tract infection symptoms). ${ }^{28}$ This is comparable with the sensitivities for the current dataset, which were $45.7 \%$ and $48.2 \%$ for the community adults and the HCW adults, respectively. Participants in this NZ seroprevalence survey were more likely to believe they had been infected if they had symptoms commonly advertised by public health campaigns as being linked with the flu. However, these symptom profiles were not significantly associated with seropositivity. This finding is consistent with a recent systematic review of symptoms in volunteer challenge studies, where nearly one in three participants demonstrated no clinical symptoms of influenza despite laboratory confirmed infection. ${ }^{29}$ The authors of that study questioned whether naturally acquired influenza might produce more marked symptoms. Our study would appear to show that this is not the case, at least for pandemic H1N1 influenza. 


\section{Implications for clinicians and policymakers}

These study findings raise important questions for pandemic control polices. On the positive side, they show that the NZ public has absorbed a fairly coherent ILI case definition that includes the symptoms traditionally linked with influenza. Unfortunately, we have demonstrated that this generic picture of ILI is a poor predicator of influenza infection. The classic symptoms of influenza are non-specific and accompany other infections commonly seen during the influenza season. A systematic review comparing influenza symptoms to independent criterion standards for influenza highlighted that epidemiological data (for example, reports of regional influenza patterns) were probably more useful than clinical indicators for predicting whether an individual had influenza. ${ }^{30}$ In addition, daily temperature measurement plus reporting of respiratory symptoms resulted in reduced transmission of $\mathrm{H} 1 \mathrm{~N} 1$ virus. ${ }^{27}$ It is also useful to note that HCW perform no better than non-professionals: the PPV of an ILI diagnosis by a HCW was $30.1 \%$. Interestingly, this value is similar to the PPV of clinical diagnosis by a GP for patients presenting to sentinel sites over the same period in 2009 (31.3\% based on 624 viruses from 1993 swabs received). ${ }^{19}$ These findings reinforce public health advice during the pandemic that patients should seek medical care on the basis of disease severity rather than for the purpose of diagnosis.

\section{Further research}

Given the importance of self-diagnosis to containment and mitigation measures, further investigations around the low accuracy of self-diagnosis would be useful. Priorities for such research could include more in-depth qualitative investigation of patient reports of influenza, prospective exploration of patient self-diagnosis at the time of respiratory infection, and variations in self-diagnosis by ethnicity, socioeconomic status and age, particularly given the differential distribution of respiratory illness across these groups (our sample was not sufficiently large to enable these analyses). ${ }^{11}$ The presenting symptoms of influenza may vary depending on the type of influenza responsible. In Singapore, H1N1 and seasonal influenza had different symptom profiles, with fever and runny nose being more common among seasonal influenza cases ${ }^{31}$ and the prevalence of specific symptoms among H1N1 cases also varied between studies, ${ }^{32-34}$ so further exploration is warranted.

Acknowledgements The authors acknowledge other members of the Pandemic Influenza Inequalities Research Group (Ricci Harris, Melissa McLeod, Tolotea Lanumata, Lucy Telfar Barnard, Jane Zhang, Colin McArthur, Thomas Love, Geoff Mercer) for helpful comments on the draft of this paper.

Correction notice The "To cite: ..." information and running footer in this article have been updated with the correct volume number (volume 1).

Funding This work was supported by the Health Research Council (NZ). Competing interests None.

Ethics approval This study was conducted with the approval of the Multiregional Ethics Committee of the NZ Ministry of Health (MEC/09/09/106).
Contributors AJ devised and led the study, guarantees the report and is the corresponding author. MGB refined the design. JS carried out the data analysis. AJ, JS and MGB prepared the manuscript. QSH and DB managed the seroprevalence study. All authors contributed to writing and revising the report.

Provenance and peer review Not commissioned; externally peer reviewed.

Data sharing statement No additional data available.

\section{REFERENCES}

1. Centers for Disease Control and Prevention. Interim Guidance on Infection Control Measures for 2009 H1N1 Influenza in Healthcare Settings, Including Protection of Healthcare Personnel, 2009. http:// www.cdc.gov/h1n1flu/guidelines_infection_control.htm (accessed 16 Nov 2009).

2. Bent S, Nallamothu BK, Simel DL, et al. Does this woman have an acute uncomplicated urinary tract infection? JAMA 2002;287:2701-10.

3. Gupta K, Hooton TM, Roberts PL, et al. Patient-initiated treatment of uncomplicated recurrent urinary tract infections in young women. Ann Intern Med 2001;135:9-16.

4. Roy S, Caillouette JC, Faden JS, et al. The role of an over-thecounter vaginal $\mathrm{pH}$ self-test device package insert: can subjects learn what the device is for and how to use it? Am J Obstet Gynecol 2005;192:1963-7; discussion 7-9.

5. Whitty CJM, Armstrong M, Behrens $\mathrm{RH}$. Self-testing for falciparum malaria with antigen-capture cards by travelers with symptoms of malaria. Am J Trop Med Hyg 2000;63:295-7.

6. Jelinek T, Amsler L, Grobusch MP, et al. Self-use of rapid tests for malaria diagnosis by tourists. Lancet 1999;354:1609.

7. Balint M. The Doctor, his Patient and the IIIness. 2nd edn. Kent England: Pitman Medical, 1964.

8. Blaxter M. Diagnosis as category and process: the case of alcoholism. Soc Sci Med 1978;12:9-17.

9. Jutel A. Sociology of diagnosis: a preliminary review. Sociol Health IIIn 2009;31:278-99.

10. Brown P. Naming and framing: the social construction of diagnosis and illness. J Health Soc Behav 1995:34-52.

11. Bondaranayake D, Huang QS, Bissielo A, et al; $09 \mathrm{H} 1 \mathrm{~N} 1$ Serosurvey Investigation Team. Risk factors and immunity in a nationally representative population following the 2009 influenza $A(H 1 N 1)$ pandemic. PLoS One 2010;5:e13211.

12. Baker MG, Wilson N, Huang QS, et al. Pandemic influenza $A(H 1 N 1) v$ in New Zealand: the experience from April to August 2009. Euro Surveill 2009;14:19319.

13. Institute of Environmental Science and Research Ltd. Sentine/ Surveillance. Wellington, NZ: Surveillance, 2010. http://www.surv.esr cri.nz/public_health_surveillance/influenza.php\#Sentinel (accessed 15 Mar 2010).

14. Ministry of Health. Guidance on the diagnosis and management of pandemic influenza H1N1. Wellington: Department of Population Health, 2010.

15. Salmond C, Crampton P, Atkinson J. NZDep2006 Index of Deprivation Wellington. Department of Public Health, University of Otago, 2007. http://www.uow.otago.ac.nz/academic/dph/research/ NZDep/NZDep2006\%20research\%20report\%2004\%20September\% 202007.pdf.

16. Ministry of Health. Ethnicity Data Protocols for the Health and Disability Sector. Wellington: Ministry of Health, 2004.

17. Rao JN, Scott AJ. On chi-squared tests for multiway contingency tables with proportions estimated from survey data. Ann Stat 1984;12:46-60.

18. Houlihan CF, Patel S, Price DA et al. A/H1N1 flu pandemic. Life threatening infections labelled swine flu. BMJ 2010;340:c137.

19. Lopez L, Huang QS. Influenza in New Zealand in 2009. Wellington ESR, 2010.

20. Friesema IH, Koppeschaar CE, Donker GA, et al. Internet-based monitoring of influenza-like illness in the general population: Experience of five influenza seasons in the Netherlands. Vaccine 2009;27:6353-7.

21. Tilston NL, Eames KT, Paolotti D, et al. Internet-based surveillance of Influenza-like-illness in the UK during the $2009 \mathrm{H} 1 \mathrm{~N} 1$ influenza pandemic. BMC Public Health 2010;10:650.

22. Anon. Seroepidemiological studies of pandemic influenza $A(\mathrm{H} 1 \mathrm{~N} 1)$ 2009 virus (In English, French). Wkly Epidemiol Rec 2010;85:229-35

23. Hancock K, Veguilla V, Lu X, et al. Cross-reactive antibody responses to the 2009 pandemic $\mathrm{H} 1 \mathrm{~N} 1$ influenza virus. $N$ Engl J Med 2009;361:1945-52.

24. Miller E, Hoschler K, Hardelid $P$, et al. Incidence of 2009 pandemic influenza A H1N1 infection in England: a cross-sectional serological study. Lancet 2010;375:1100-8. 
25. Gilbert GL, Cretikos MA, Hueston L, et al. Influenza A (H1N1) 2009 antibodies in residents of New South Wales, Australia, after the first pandemic wave in the 2009 southern hemisphere winter. PLoS One 2010;5:e12562.

26. Wu JT, Ma ES, Lee CK, et al. The infection attack rate and severity of 2009 pandemic H1N1 influenza in Hong Kong. Clin Infect Dis 2010;51:1184-91.

27. Lee VJ, Yap J, Cook AR, et al. Effectiveness of public health measures in mitigating pandemic influenza spread: a prospective sero-epidemiological cohort study. $J$ Infect Dis 2010;202:1319-26.

28. Aho M, Lyytikainen O, Nyholm JE, et al. Outbreak of 2009 pandemic influenza $A(\mathrm{H} 1 \mathrm{~N} 1)$ in a Finnish garrison-a serological survey. Euro Surveill 2010;15:19709.

29. Carrat F, Vergu E, Ferguson NM, et al. Time lines of infection and disease in human influenza: a review of volunteer challenge studies. Am J Epidemiol 2008;167:775-85.
30. Call SA, Vollenweider MA, Hornung CA, et al. Does this patient have influenza? JAMA 2005;293:987-97.

31. Tang JW, Tambyah PA, Lai FY, et al. Differing symptom patterns in early pandemic vs seasonal influenza infections. Arch Intern Med 2010;170:861-7.

32. Cao B, Li XW, Mao Y, et al; National Influenza A Pandemic (H1N1) 2009 Clinical Investigation Group of China. Clinical features of the initial cases of 2009 pandemic influenza A (H1N1) virus infection in China. N Engl J Med 2009;361:2507-17.

33. World Health Organisation. Human infection with new influenza A (H1N1) virus: clinical observations from a school-associated outbreak in Kobe, Japan, May 2009 (In English, French). Wkly Epidemiol Rec 2009;84:237-48.

34. Perez-Padilla R, de la Rosa-Zamboni D, Ponce de Leon S, et al; INER Working Group on Influenza. Pneumonia and Respiratory Failure from Swine-Origin Influenza A (H1N1) in Mexico. $N$ Engl J Med 2009;361:680-9. 